\title{
Analysis model of parameters affecting cutting performance in high-speed machining
}

\author{
Yung-Cheng Wang • Chi-Hsiang Chen • Bean-Yin Lee
}

Received: 16 June 2013 / Accepted: 17 November 2013 / Published online: 20 February 2014

(C) The Author(s) 2014. This article is published with open access at Springerlink.com

\begin{abstract}
Further progress in green cutting applications depends on the innovativeness of machine tools, advances in tool development, and, especially, more complex tool and cutting technologies. Therefore, this study analyzes the factors influencing high-speed cutting performance. Grey relational analysis and the Taguchi method are then incorporated in the experimental plan with high-speed milling of AISI H13 tool steel. Experimental results indicate that the contributions of tool grinding precision, geometric angle, and cutting conditions to the multiple quality characteristics of high-speed milling for AISI H13 tool steel are 11.75, 9.80, and 73.11 \%, respectively. For rough machining, tool life and metal removal volume are the primary evaluation indicators and cutting parameters should be prioritized, especially cutting speed and feed per tooth. In finish machining, workpiece surface roughness is the primary evaluation indicator. Besides the selection of cutting parameters, the design and grinding of endmill are critical factors, especially the design and grinding of relief angles.
\end{abstract}

Keywords High-speed cutting · Tool grinding · Grey relational analysis $\cdot$ Surface roughness $\cdot$ Endmill

Y.-C. Wang

Institute of Mechanical Engineering, National Yunlin University of

Science and Technology, Douliu, Taiwan

C.-H. Chen $(\square)$

Institute of Mechanical and Electro-Mechanical Engineering,

National Formosa University, Huwei, Taiwan

e-mail: explorer5270@gmail.com

B.-Y. Lee

Department of Mechanical and Computer-Aided Engineering,

National Formosa University, Huwei, Taiwan

\section{Introduction}

Machine tool development is increasingly characterized by its use of high-speed technology, including high-speed machining (HSM) and high-speed cutting (HSC). In particular, these functions are extensively adopted in high-speed end milling $[1,2]$. Schulz and Moriwaki [3] defined HSC as increasing productivity, reducing cutting forces, decreasing thermal deformation of workpieces, and clamping systems, as well as improving surface roughness and stabilizing cutting. Current investigations on green cutting and cost reduction address global developmental issues. On a technical level, such issues involve precision tool design and grinding, tool coating, metallic materials, and HSC [4-7]. Related studies also offer details and reviews [8] of the various methods of predicting surface roughness for machining.

Tool manufacturing highly prioritizes the cutting edge grinding of endmills, a process which determines tool geometry, tool grinding precision, and cutting performance. Cutting edge geometry is complex and geometric shapes vary according to different tool materials. Tool grinding parameters directly influence tool grinding precision, which is based on rake face and relief face roughness. Rake face roughness primarily influences rake face and chip flow contact and directly affects tool rake face wear. Relief face roughness concerns itself with tool and workpiece surface contact and influences flank wear and workpiece surface roughness. Yin et al. [9] used a diamond grinding wheel to grind tungsten carbide rod ends of various particle sizes. Their results suggested that the material removal process is a feasible ductility removal method during ultra-precision grinding. Kwak [10] examined errors in surface grinding by using the Taguchi method and response surface method. The Taguchi method experiment indicated that the primary parameters influencing geometric errors are mainly grinding depth, followed by wheel grit. Kopac and Krajnik [11] suggested a high- 
performance grinding perspective, in which a high grinding speed during high-performance grinding can increase wheel life and production efficiency. Finally, Abdullah et al. [12] used a resin-bonded diamond grinding wheel to grind tungsten carbide alloy workpieces with $20 \%$ cobalt binding agents. That study also investigated how the grinding speed and feeding rate influence the optimal workpiece surface roughness.

Taguchi quality engineering involves a simple, efficient, and systematic experimental programming method. Integrated with an analysis of variance (ANOVA), Taguchi quality engineering can both reach the limitations of experimental conditions and reduce the sensitivity of design goals to achieve parameter variability during optimal design [13]. Based on this method, several studies have investigated and resolved the optimization of process parameters for a single quality characteristic [14-16]. Deng (1982) performed grey relational grade analysis. Systematic grey relational analysis, modeling, forecasting, and decision making were done primarily when investigating unclear system models, incomplete information, and unclear operating statuses [17]. Grey relational analysis has been widely applied in recent years for optimal process parameter designs of multiple quality characteristics for machining [18-23]. Most studies have performed optimal parameter design for flank wear and workpiece surface roughness regarding only cutting parameters and tool geometry. However, exactly how tool geometric and cutting conditions influence multiple quality characteristics for milling performance has seldom been thoroughly surveyed in tool grinding precision studies.

Tool design research has investigated how cutting parameters and tool geometry influence tool life using microendmill with diameters of $0.2 \mathrm{~mm}$ as the basis for experimental design [24]. By using $\mathrm{L}_{9}$ orthogonal arrays to plan micromilling simulations and DEFORM 2D software, this study constructed design patterns for micro-milling SKD61 (AISI H13) tool steel. The process parameters were cutting speed $(167.55,188.50$, and $209.44 \mathrm{~mm} / \mathrm{s})$, cutting depth $(0.01,0.02$, and $0.03 \mathrm{~mm})$, effective rake angle $\left(20^{\circ}, 25^{\circ}\right.$, and $\left.30^{\circ}\right)$, and relief angle $\left(7^{\circ}, 10^{\circ}\right.$, and $\left.13^{\circ}\right)$, which functioned as controllable factors. The quality characteristics were cutting force, maximum tool temperature, distance between the maximum tool temperature location and tool tip, as well as the contact length between the tool and the chip. A longer tool life is generally associated with a lower cutting force, a lower maximum tool temperature, and a greater difference between the maximum tool temperature location and tool tip, as well as the contact length between the tool and the chip. According to the ANOVA results in Table 1, cutting speed (39.307 \%) most significantly influenced multiple quality characteristics, followed by effective rank angle $(26.043 \%)$, relief angle $(17.472 \%)$, and feed per tooth $(17.178 \%)$. Therefore, the contributions of cutting parameters and tool geometry to tool life were 56.485 and $43.515 \%$, respectively.
As for tool grinding precision, an endmill relief face roughness of $0.23 \pm 0.03 \mu \mathrm{m}$ could increase workpiece surface roughness [25], as shown in Fig. 1 (initial design: relief face roughness of $0.43 \pm 0.02 \mu \mathrm{m}$, cutting speed of $251.32 \mathrm{~m} / \mathrm{min}$, feed per tooth of $0.06 \mathrm{~mm} /$ tooth, axial cutting depth of $1.5 \mathrm{~mm}$, and radial cutting depth of $0.5 \mathrm{~mm}$; experiment no. 12: relief face roughness of $0.43 \pm 0.02 \mu \mathrm{m}$, cutting speed of $251.32 \mathrm{~m} / \mathrm{min}$, feed per tooth of $0.1 \mathrm{~mm} /$ tooth, axial cutting depth of $1.0 \mathrm{~mm}$, and radial cutting depth of $0.75 \mathrm{~mm}$; optimal design: relief face roughness of $0.23 \pm 0.03 \mu \mathrm{m}$, cutting speed of $251.32 \mathrm{~m} / \mathrm{min}$, feed per tooth of $0.1 \mathrm{~mm} /$ tooth, axial cutting depth of $1.0 \mathrm{~mm}$, and radial cutting depth of $0.75 \mathrm{~mm}$ ). Thus, based on an $\mathrm{L}_{18}$ orthogonal array, HSM experiments were planned when the optimal process parameters increased the relief face roughness. The process parameters were relief face roughness $(0.23 \pm 0.03$ and $0.43 \pm 0.02 \mu \mathrm{m})$, cutting speed (251.32, 351.85, and $452.38 \mathrm{~m} / \mathrm{min})$, feed per tooth $(0.02$, 0.06 , and $0.10 \mathrm{~mm} /$ tooth $)$, axial cutting depth $(0.5,1.0$, and $1.5 \mathrm{~mm})$, and radial cutting depth $(0.50,0.75$, and $1.00 \mathrm{~mm})$. The milling performance indicators were peripheral flank wear rate, end flank wear rate, and metal removal rate, which represented a problem of multiple quality characteristics. Consequently, grey relational grades denoted the multiple quality characteristics. The grey relational grade ANOVA indicated that the cutting speed $(58.52 \%)$ and feed per tooth $(17.94 \%)$ most significantly influenced the multiple quality characteristics. The contribution of relief face roughness was $3.87 \%$. However, the endmill with a relief face roughness of $0.23 \pm 0.03 \mu \mathrm{m}$ for grinding increased the cost by $53.33 \%$. Therefore, in rough machining, grinding conditions with a relief face roughness of $0.43 \pm 0.02 \mu \mathrm{m}$ can increase tool grinding efficiency.

Based on the above analyses, tool grinding precision, tool geometry, and cutting parameters influenced the milling performance of AISI H13 tool steel. Therefore, this study attempted to determine the influence weighting of these various factors. The factors influencing cutting performance characteristics were subsequently divided into three groups: tool grinding precision, tool geometry, and cutting conditions. Additionally, the correlations between the factors and their influence on HSC performance were analyzed using the grey relational analysis and the Taguchi method. Finally, the factors in single quality and multiple quality characteristics that influenced high-speed cutting performance characteristics were analyzed using ANOVA.

\section{Analysis methods}

\subsection{Signal-to-noise ratio}

The Taguchi method is a simple and effective solution for parameter design and experimental planning [13]. In this 
Table 1 Results of the analysis of variance [24]

\begin{tabular}{llllll}
\hline Symbol & Simulation parameter & $\begin{array}{l}\text { Degree of } \\
\text { freedom }\end{array}$ & $\begin{array}{l}\text { Sum of } \\
\text { square }\end{array}$ & $\begin{array}{l}\text { Mean } \\
\text { square }\end{array}$ & $\begin{array}{l}\text { Contribution } \\
(\%)\end{array}$ \\
\hline A & Cutting speed (m/min) & 2 & 0.0186 & 0.0093 & 39.307 \\
B & Cutting depth (mm) & 2 & 0.0081 & 0.0041 & 17.178 \\
C & Effective rake angle (deg) & 2 & 0.0123 & 0.0062 & 26.043 \\
D & Relief angle (deg) & 2 & 0.0083 & 0.0041 & 17.472 \\
Total & & 8 & 1.8130 & & 100.000 \\
\hline
\end{tabular}

method, the signal-to-noise $(\mathrm{S} / \mathrm{N})$ ratio is used to represent a performance characteristic, in which the largest value of $\mathrm{S} / \mathrm{N}$ ratio is required. Three $\mathrm{S} / \mathrm{N}$ ratios are the lower-the-better, the higher-the-better, and the nominal-the-better. The $\mathrm{S} / \mathrm{N}$ ratio with a lower-the-better characteristic can be illustrated as follows:

$\eta_{i j}=-10 \log \left(\frac{1}{n} \sum_{j=1}^{n} y_{i j}^{2}\right)$

The $\mathrm{S} / \mathrm{N}$ ratio with a higher-the-better characteristic can be expressed as follows:

$\eta_{i j}=-10 \log \left(\frac{1}{n} \sum_{j=1}^{n} \frac{1}{y_{i j}^{2}}\right)$

$y_{i j}$ is the $i$ th experiment at the $j$ th test, and $n$ is the total number of tests; in this study, $n=2$.

\subsection{Grey relational analysis}

Grey relational analysis initially generates data preprocessing to normalize the raw data. Here, the $\mathrm{S} / \mathrm{N}$ ratio is linearly normalized in the range between 0 and 1 , which is also called grey relational generating [17]. The normalized $\mathrm{S} / \mathrm{N}$ ratio $x_{i j}$ for the $i$ th performance characteristic in the $j$ th experiment can be described as follows:

$x_{i j}=\frac{\eta_{i j}-\min _{j} \eta_{i j}}{\max _{j} \eta_{i j}-\min _{j} \eta_{i j}}$

where $i=1, \ldots, m$ and $j=1, \ldots, n . m$ denotes the number of experimental data items and $n$ represents the number of parameters, with $m=18$ and $n=2$ in this study. Basically, a larger normalized $\mathrm{S} / \mathrm{N}$ ratio corresponds to a better performance, and the best normalized $\mathrm{S} / \mathrm{N}$ ratio is equal to unity.

In grey relational analysis, the evaluation of the relevancy between two systems or two sequences is defined as the grey relational grade. The local grey relation measurement refers to a situation in which only one sequence follows data preprocessing. The grey relational coefficient $\zeta_{i j}$ for the $i$ th performance characteristic in the $j$ th experiment can be expressed as follows:

$\zeta_{i j}=\frac{\min _{i} \min _{j}\left|x_{i}^{0}-x_{i j}\right|+\zeta \max _{i} \max _{j}\left|x_{i}^{0}-x_{i j}\right|}{\left|x_{i}^{0}-x_{i j}\right|+\zeta \max _{i} \max _{j}\left|x_{i}^{0}-x_{i j}\right|}$

where $x_{i}^{0}$ is the ideal sequence for the $i$ th performance characteristic, $x_{i j}$ represents the comparability sequence, and $\zeta$ refers to the distinguishing coefficient which is defined in the range $0 \leqq \zeta \leqq 1$; in this study, $\zeta=0.5$. (a)

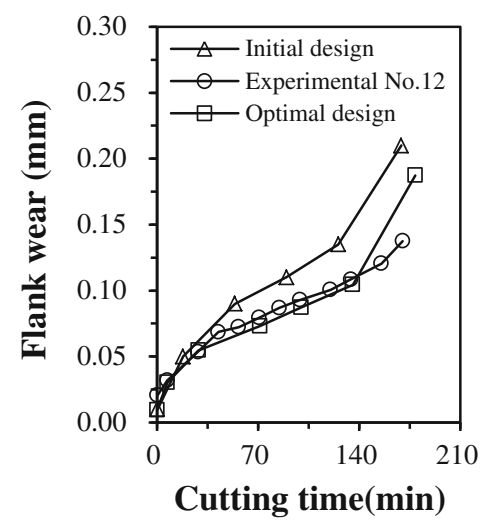

(b)

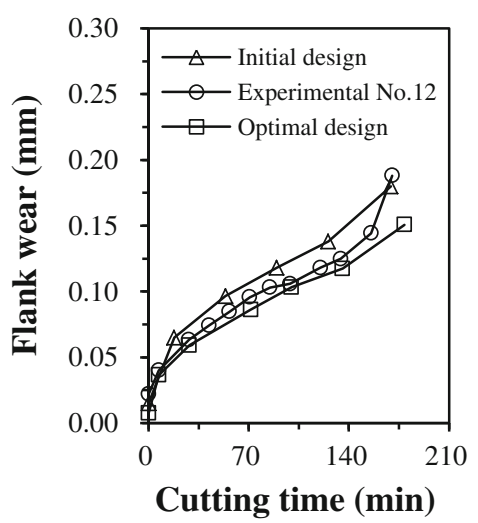

(c)

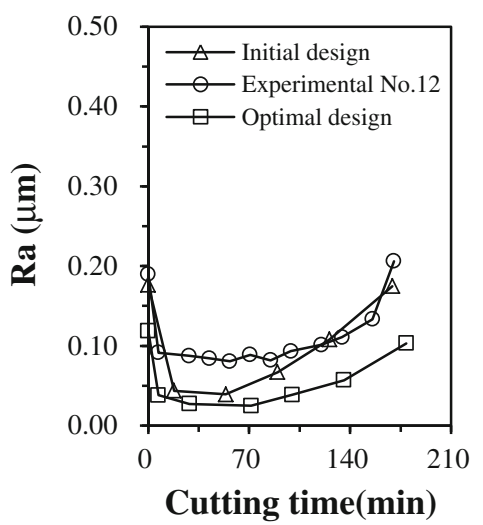

Fig. 1 Effect of cutting time on cutting performance. a Flank wears of peripheral cutting edge. b Flank wears of end cutting edge. c Surface roughness of workpiece [25] 
Fig. 2 Geometrical parameters of an endmill

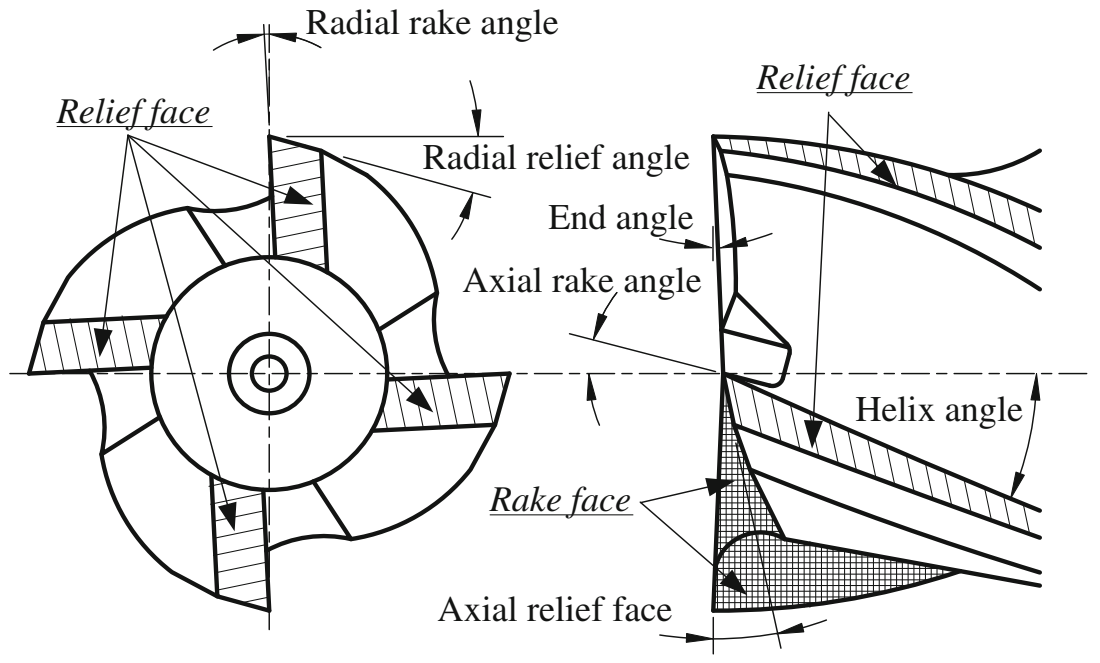

The grey relational grade is a weighting sum of the grey relational coefficients. It is defined as follows:

$\gamma_{j}=\frac{1}{m} \sum_{k=1}^{m} \beta_{k} \zeta_{i j} \sum_{k=1}^{m} \beta_{k}=1$

where $\gamma_{j}$ is the grey relational grade for the $j$ th experiment, $\beta_{k}$ denotes the weighting value of the $k$ th performance characteristic, and $m$ is the number of performance characteristic. Then the grey relational grade $\gamma_{j}$ represents the level of correlation between the ideal sequence and the comparability sequence. In other words, optimization of the complicated multiple performance characteristics can be converted into the optimization of a single grey relational grade.

\section{Experimental designs and results}

\subsection{Experimental designs}

This study divided the parameters influencing cutting performance into three groups: endmill grinding precision, tool geometry, and cutting parameters. Constant parameters of the experiment were the tool material with tungsten carbide AF-K44, the coating of TiAlN, and the cutting material of Hitachi DAC tool steel (AISI H13). The endmills have the following dimensions: number of four flutes, diameter of $8 \mathrm{~mm}$, helix angle of $35^{\circ}$, end angle of $1.5^{\circ}$, and nose radius of $0.3 \mathrm{~mm}$. Figure 2 shows the corresponding geometrical profile of an endmill. Details regarding the tool design and grinding method can be found in [26].

The control process parameters influencing cutting performance were rake face roughness (A), relief face roughness (B), rake angle (C), relief angle (D), cutting speed (E), feed per tooth $(\mathrm{F})$, axial cutting depth $(\mathrm{G})$, and radial cutting depth $(\mathrm{H})$. Table 2 lists the experimental parameters and their levels. The grinding wheel for the tool grinding was an SDC-series grinding wheel produced by Taiwan Diamond Industrial Co., Ltd. Grinding conditions for the endmill surface roughness of controllable factors A and B were as follows: A1: D46, a grinding speed of $900 \mathrm{~m} / \mathrm{min}$, and a feeding rate of $100 \mathrm{~mm} /$ min; A2: D64, a grinding speed of $1,500 \mathrm{~m} / \mathrm{min}$, and a feeding rate of $400 \mathrm{~mm} / \mathrm{min}$; B1: D54, a grinding speed of $1,750 \mathrm{~m} /$ min, and a feeding rate of $10 \mathrm{~mm} / \mathrm{min}$; B2: D54, a grinding speed of $1,350 \mathrm{~m} / \mathrm{min}$, and a feeding rate of $150 \mathrm{~mm} / \mathrm{min}$; and B3: D54, a grinding speed of $1,000 \mathrm{~m} / \mathrm{min}$, and a feeding rate
Table 2 Processing parameters and their levels

N/A not applicable

\begin{tabular}{lllll}
\hline Symbol & Processing parameter & Level 1 & Level 2 & Level 3 \\
\hline A & Rake face roughness $(\mu \mathrm{m})$ & $0.50 \pm 0.03$ & $1.50 \pm 0.03$ & N/A \\
B & Relief face roughness $(\mu \mathrm{m})$ & $0.50 \pm 0.03$ & $1.00 \pm 0.03$ & $1.50 \pm 0.03$ \\
C & Rake angle $(\mathrm{deg})$ & $1.36 \pm 0.1$ & $9.76 \pm 0.1$ & $17.84 \pm 0.1$ \\
D & Relief angle $(\mathrm{deg})$ & $5.00 \pm 0.1$ & $8.00 \pm 0.1$ & $11.00 \pm 0.1$ \\
E & Cutting speed $(\mathrm{m} / \mathrm{min})$ & 251.32 & 351.85 & 452.38 \\
F & Feed per tooth $(\mathrm{mm} / \mathrm{t})$ & 0.03 & 0.05 & 0.07 \\
G & Axial cutting depth $(\mathrm{mm})$ & 0.50 & 1.00 & 1.50 \\
$\mathrm{H}$ & Radial cutting depth $(\mathrm{mm})$ & 0.50 & 0.75 & 1.00 \\
\hline
\end{tabular}


of $400 \mathrm{~mm} / \mathrm{min}$. For the roughness measurement of the rake face and relief face, the endmill was placed in a surface roughness tester (Surfcorder SEF-4000). The expressed surface roughness in this article was the arithmetic mean deviation of the surface roughness profile, Ra. The measurement parameters were cutoff $=0.08 \mathrm{~mm}$, E.length $=$ cutoff $\times 5$, and speed $=0.1 \mathrm{~m} / \mathrm{s}$. Due to the endmill with four cutter edges and five points measured on each cutter edge, the average of these 20 measurands represents surface roughness $\mathrm{Ra}$ at 20 different rake faces and relief face locations.

Selection of the orthogonal array involves the total degree of freedom of the processing parameters. Here, a processing parameter is available for two levels, and seven processing parameters are appropriate for three levels. In this experimental arrangement, the interaction among the processing parameters is neglected. The freedom of processing parameter is level number minus one. Here, the total freedoms are 15, explaining the use of $\mathrm{L}_{18}\left(2^{1} \times 3^{7}\right)$ orthogonal array in the experimental plan. According to $\mathrm{L}_{18}$ orthogonal array, Table 3 shows the configuration of processing parameters.

During the experiment, the five-axis computer numerical control (CNC) tool grinder (TOPWORK TG-5 Plus) was first adopted for tool grinding. The endmill was sequentially subjected to grinding experiments based on the grinding conditions for A1-B3 in coordination with the experimental layout shown in Table 3. Table 2 lists the tool grinding times. During

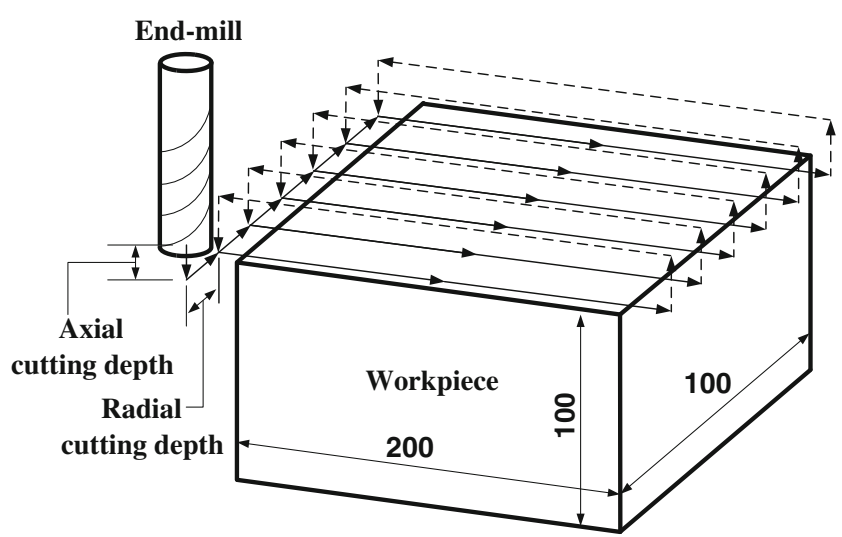

Fig. 3 High-speed milling method

the cutting experiments, tool elongation was $20 \mathrm{~mm}$ and the dynamic balance of the tool was required to be less than $0.02 \mathrm{G}$. The cutting experiments were performed in a CNC machining center (DMU 60TN) by conventional milling and using compressed air. Figure 3 shows the HSC process. For rough milling, tool life and metal removal volume are the primary evaluation indicators. In finish machining, workpiece surface roughness is the primary evaluation indicator. Generally, longer cutting times are associated with a longer tool life. As is well known, longer cutting times are generally associated with a longer tool life. Therefore, in this study,

Table 3 Experimental layout and results

\begin{tabular}{|c|c|c|c|c|c|c|c|c|c|c|c|c|c|}
\hline \multirow[t]{2}{*}{ No. } & \multicolumn{8}{|c|}{ Experimental layout } & \multicolumn{5}{|c|}{ Experimental results } \\
\hline & A & B & $\mathrm{C}$ & $\mathrm{D}$ & $\mathrm{E}$ & $\mathrm{F}$ & G & $\mathrm{H}$ & $\begin{array}{l}\text { Grinding time } \\
\text { (s) }\end{array}$ & $\begin{array}{l}\text { Cutting time } \\
\text { (min) }\end{array}$ & $\begin{array}{l}\text { FWR } \\
(\mathrm{mm} / \mathrm{min}) \times 10^{-4}\end{array}$ & $\begin{array}{l}\text { WSR } \\
(\mu \mathrm{m})\end{array}$ & $\begin{array}{l}\text { TRV } \\
\left(\mathrm{mm}^{3}\right)\end{array}$ \\
\hline 1 & 1 & 1 & 1 & 1 & 1 & 1 & 1 & 1 & 1,660 & 137.70 & 12.04 & 0.48 & 41,310 \\
\hline 2 & 1 & 1 & 2 & 2 & 2 & 2 & 2 & 2 & 1,660 & 91.60 & 16.18 & 0.52 & 192,355 \\
\hline 3 & 1 & 1 & 3 & 3 & 3 & 3 & 3 & 3 & 1,660 & 76.70 & 19.22 & 0.50 & 579,852 \\
\hline 4 & 1 & 2 & 1 & 1 & 2 & 2 & 3 & 3 & 1,010 & 61.20 & 26.03 & 0.57 & 257,040 \\
\hline 5 & 1 & 2 & 2 & 2 & 3 & 3 & 1 & 1 & 1,010 & 85.51 & 17.48 & 0.55 & 107,740 \\
\hline 6 & 1 & 2 & 3 & 3 & 1 & 1 & 2 & 2 & 1,010 & 142.49 & 10.31 & 0.53 & 128,237 \\
\hline 7 & 1 & 3 & 1 & 2 & 1 & 3 & 2 & 3 & 912 & 155.10 & 11.30 & 0.66 & 434,286 \\
\hline 8 & 1 & 3 & 2 & 3 & 2 & 1 & 3 & 1 & 912 & 132.75 & 11.13 & 0.62 & 167,265 \\
\hline 9 & 1 & 3 & 3 & 1 & 3 & 2 & 1 & 2 & 912 & 61.35 & 26.24 & 0.44 & 82,824 \\
\hline 10 & 2 & 1 & 1 & 3 & 3 & 2 & 2 & 1 & 1,400 & 107.74 & 14.33 & 0.55 & 193,931 \\
\hline 11 & 2 & 1 & 2 & 1 & 1 & 3 & 3 & 2 & 1,400 & 185.98 & 8.69 & 0.38 & 585,851 \\
\hline 12 & 2 & 1 & 3 & 2 & 2 & 1 & 1 & 3 & 1,400 & 57.35 & 24.54 & 0.47 & 48,175 \\
\hline 13 & 2 & 2 & 1 & 2 & 3 & 1 & 3 & 2 & 762 & 65.97 & 21.05 & 0.65 & 160,296 \\
\hline 14 & 2 & 2 & 2 & 3 & 1 & 2 & 1 & 3 & 762 & 171.81 & 9.11 & 0.58 & 171,808 \\
\hline 15 & 2 & 2 & 3 & 1 & 2 & 3 & 2 & 1 & 762 & 65.89 & 24.80 & 0.44 & 129,150 \\
\hline 16 & 2 & 3 & 1 & 3 & 2 & 3 & 1 & 2 & 672 & 130.66 & 13.24 & 0.62 & 192,075 \\
\hline 17 & 2 & 3 & 2 & 1 & 3 & 1 & 2 & 3 & 672 & 38.16 & 34.80 & 0.56 & 82,416 \\
\hline 18 & 2 & 3 & 3 & 2 & 1 & 2 & 3 & 1 & 672 & 128.65 & 11.21 & 0.53 & 192,974 \\
\hline
\end{tabular}


Fig. 4 Features of the flank wear land on the endmill

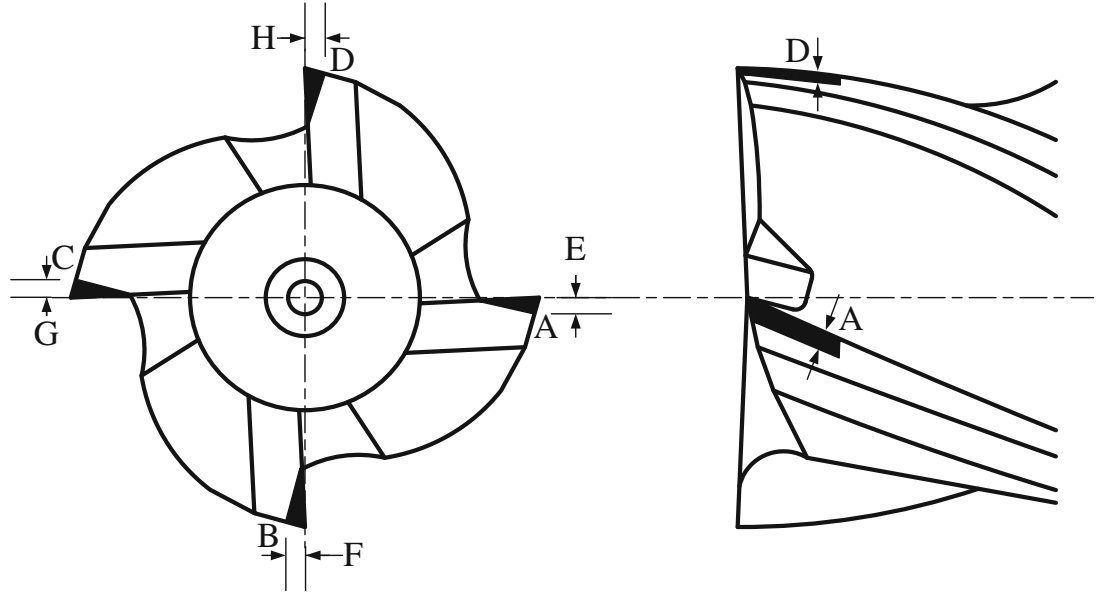

flank wear rate was used as a quality characteristic of tool life, including peripheral and end flank wear rates. Cutting performance was then evaluated by using flank wear rate (FWR), workpiece surface roughness (WSR), and total removal volume (TRV).

\subsection{Experimental results}

The milling experiments were performed based on the experimental layout in Table 2. Each process parameter combination was repeated twice. Tool life was estimated based on the ISO3002/1 standard regarding flank wear $\left(V_{\mathrm{B}}\right)$ of $0.2 \mathrm{~mm}$.
Cutting time was calculated when the experiments were completed. The endmills were placed under a microscope (OLYMPUS STM5-BDZ) at a magnification of $\times 100$ to measure flank wear. Figure 4 displays the flank wear measurement positions. Peripheral flank wear $w_{\mathrm{p}}$ was calculated as the mean values of $\mathrm{A}, \mathrm{B}, \mathrm{C}$, and $\mathrm{D}$, whereas end flank wear $w_{\mathrm{e}}$ was calculated as the mean values of E, F, G, and $H$. The average width of total flank wear (FW) can be expressed as follows:

$\mathrm{FW}=\left(w_{\mathrm{p}}+w_{\mathrm{e}}\right) / 2$

Table 4 Grey relational analysis

\begin{tabular}{|c|c|c|c|c|c|c|c|c|c|c|c|}
\hline \multirow[t]{2}{*}{ No. } & \multicolumn{3}{|c|}{ Sequences of $\mathrm{S} / \mathrm{N}$ ratio } & \multicolumn{3}{|c|}{ Normalized $\mathrm{S} / \mathrm{N}$ ratio } & \multicolumn{3}{|c|}{ Grey relational coefficient } & \multirow{2}{*}{$\begin{array}{l}\text { Grey relational } \\
\text { grade }\end{array}$} & \multirow[t]{2}{*}{ Orders } \\
\hline & FWR & WSR & TRV & FWR & WSR & TRV & FWR & WSR & TRV & & \\
\hline 1 & -21.610 & 6.334 & 92.321 & 0.765 & 0.570 & 0.000 & 0.680 & 0.538 & 0.333 & 0.517 & 9 \\
\hline 2 & -24.182 & 5.744 & 105.682 & 0.552 & 0.449 & 0.580 & 0.527 & 0.476 & 0.544 & 0.516 & 10 \\
\hline 3 & -25.676 & 5.969 & 115.266 & 0.428 & 0.495 & 0.996 & 0.466 & 0.498 & 0.992 & 0.652 & 2 \\
\hline 4 & -28.310 & 4.957 & 108.200 & 0.209 & 0.288 & 0.689 & 0.387 & 0.412 & 0.617 & 0.472 & 14 \\
\hline 5 & -24.853 & 5.155 & 100.647 & 0.496 & 0.328 & 0.361 & 0.498 & 0.427 & 0.439 & 0.455 & 15 \\
\hline 6 & -20.267 & 5.582 & 102.160 & 0.876 & 0.416 & 0.427 & 0.802 & 0.461 & 0.466 & 0.576 & 5 \\
\hline 7 & -21.061 & 3.557 & 112.756 & 0.81 & 0.000 & 0.887 & 0.725 & 0.333 & 0.816 & 0.625 & 3 \\
\hline 8 & -20.926 & 4.099 & 104.468 & 0.822 & 0.111 & 0.527 & 0.737 & 0.360 & 0.514 & 0.537 & 7 \\
\hline 9 & -28.380 & 7.113 & 98.363 & 0.203 & 0.730 & 0.262 & 0.386 & 0.650 & 0.404 & 0.480 & 13 \\
\hline 10 & -23.124 & 5.250 & 105.753 & 0.639 & 0.348 & 0.583 & 0.581 & 0.434 & 0.545 & 0.520 & 8 \\
\hline 11 & -18.779 & 8.427 & 115.356 & 1.000 & 1.000 & 1.000 & 1.000 & 1.000 & 1.000 & 1.000 & 1 \\
\hline 12 & -27.798 & 6.505 & 93.656 & 0.252 & 0.605 & 0.058 & 0.401 & 0.559 & 0.347 & 0.435 & 16 \\
\hline 13 & -26.466 & 3.798 & 104.098 & 0.362 & 0.050 & 0.511 & 0.439 & 0.345 & 0.506 & 0.430 & 17 \\
\hline 14 & -19.193 & 4.702 & 104.701 & 0.966 & 0.235 & 0.537 & 0.936 & 0.395 & 0.519 & 0.617 & 4 \\
\hline 15 & -27.888 & 7.109 & 102.222 & 0.244 & 0.729 & 0.430 & 0.398 & 0.649 & 0.467 & 0.505 & 12 \\
\hline 16 & -22.441 & 4.170 & 105.669 & 0.696 & 0.126 & 0.579 & 0.622 & 0.364 & 0.543 & 0.510 & 11 \\
\hline 17 & -30.832 & 5.002 & 98.320 & 0.000 & 0.297 & 0.260 & 0.333 & 0.416 & 0.403 & 0.384 & 18 \\
\hline 18 & -20.992 & 5.474 & 105.710 & 0.816 & 0.394 & 0.581 & 0.731 & 0.452 & 0.544 & 0.576 & 6 \\
\hline
\end{tabular}


Table 5 ANOVA for flank wear

\begin{tabular}{lllllll}
\hline Processing parameter & $\begin{array}{l}\text { Degree of } \\
\text { freedom }\end{array}$ & $\begin{array}{l}\text { Sum of } \\
\text { square }\end{array}$ & $\begin{array}{l}\text { Mean } \\
\text { square }\end{array}$ & $F$ value & $P$ value & $\begin{array}{l}\text { Contribution } \\
(\%)\end{array}$ \\
\hline Rake face roughness & 1 & 0.281 & 0.281 & 0.202 & 0.697 & 0.13 \\
Relief face roughness & 2 & 2.845 & 1.423 & 1.025 & 0.494 & 1.27 \\
Rake angle & 2 & 12.868 & 6.434 & 4.637 & 0.177 & 5.75 \\
Relief angle & 2 & 48.988 & 24.494 & 17.654 & 0.054 & 21.87 \\
Cutting speed & 2 & 130.018 & 65.009 & 46.855 & 0.021 & 58.06 \\
Feed per tooth & 2 & 4.324 & 2.162 & 1.558 & 0.391 & 1.93 \\
Axial cutting depth & 2 & 3.209 & 1.605 & 1.156 & 0.464 & 1.43 \\
Radial cutting depth & 2 & 18.640 & 9.320 & 6.717 & 0.130 & 8.32 \\
Error & 2 & 2.775 & 1.387 & & & 1.24 \\
Total & 17 & 223.948 & & & & 100.00 \\
\hline
\end{tabular}

$F_{0.1}(1,2)=8.53, F_{0.1}(2,2)=9.00$

The flank wear rates were calculated using Eq. (7). Additionally, the workpieces were placed in a surface roughness tester (Surfcorder SE-4000) to measure the surface roughness $\mathrm{Ra}$. The measurement parameters were cutoff $=0.8 \mathrm{~mm}$, E.length $=$ cutoff $\times 5$, and speed $=0.1 \mathrm{~m} / \mathrm{s}$. Surface roughness of the workpiece was measured when the cumulative cutting time reached $10 \mathrm{~min}$, with ten points measured each time. Mean values were obtained after the end of tool life. Table 3 summarizes the experimental results.

$\mathrm{FWR}=\frac{\text { Average width off lank wear }(\mathrm{FW})}{\text { Cuttingtime }}$

\section{Discussion}

\subsection{Single performance characteristics analysis}

The performance characteristics are first converted into $\mathrm{S} / \mathrm{N}$ ratio by using the Taguchi method. With $\mathrm{S} / \mathrm{N}$ quantity, optimal performance and minimal variance can be designed. A longer tool life generally implies a higher metal removal volume, lower workpiece surface roughness, and improved cutting performance. Therefore, FWR and WSR should be minimum and TRV should be maximum. The results in Table 4 are substituted in Eqs. (1) and (2). Table 4 lists the $\mathrm{S} / \mathrm{N}$ ratios of FRW, WSR, and TRV. The S/N ratio can be used for performance analysis. Moreover, a higher $\mathrm{S} / \mathrm{N}$ ratio should improve the performance characteristics.

The ANOVA results show the degree of variation and contribution of each process parameter to the quality objectives. Tables 5, 6, and 7 summarize the ANOVA results for each quality characteristic regarding the HSC of AISI H13 tool steel. Table 5 indicates that the primary factors influencing flank wear rate are cutting speed (contribution 58.057 \%) and relief angle $(21.875 \%)$. Rake face roughness, relief face roughness, rake angle, feed per tooth, axial cutting depth, and radial cutting depth are not significant factors. Table 6 reveals that the primary factors influencing workpiece surface roughness are relief angle (32.349 \%), rake angle (28.428\%), and relief face roughness $(26.080 \%)$. Rake face roughness, cutting speed, feed per tooth, radial cutting depth, and axial cutting depth are not significant factors. In terms of cutting
Table 6 ANOVA for workpiece surface roughness

$F_{0.1}(1,2)=8.53, F_{0.1}(2,2)=9.00$

\begin{tabular}{lllllll}
\hline Processing parameter & $\begin{array}{l}\text { Degree of } \\
\text { freedom }\end{array}$ & $\begin{array}{l}\text { Sum of } \\
\text { square }\end{array}$ & $\begin{array}{l}\text { Mean } \\
\text { square }\end{array}$ & $F$ value & $P$ value & $\begin{array}{l}\text { Contribution } \\
(\%)\end{array}$ \\
\hline Rake face roughness & 1 & 0.206 & 0.206 & 0.740 & 0.480 & 0.75 \\
Relief face roughness & 2 & 7.176 & 3.588 & 12.871 & 0.072 & 26.08 \\
Rake angle & 2 & 7.822 & 3.911 & 14.030 & 0.067 & 28.43 \\
Relief angle & 2 & 8.901 & 4.451 & 15.965 & 0.059 & 32.35 \\
Cutting speed & 2 & 0.306 & 0.153 & 0.549 & 0.646 & 1.11 \\
Feed per tooth & 2 & 0.801 & 0.400 & 1.436 & 0.410 & 2.91 \\
Axial cutting depth & 2 & 0.267 & 0.134 & 0.480 & 0.676 & 0.97 \\
Radial cutting depth & 2 & 1.479 & 0.739 & 2.652 & 0.274 & 5.37 \\
Error & 2 & 0.558 & 0.279 & & & 2.03 \\
Total & 17 & 27.516 & & & & 100.00 \\
\hline
\end{tabular}


Table 7 ANOVA for total removal volumes

$F_{0.1}(1,2)=8.53, F_{0.1}(2,2)=9.00$

\begin{tabular}{lllllll}
\hline Processing parameter & $\begin{array}{l}\text { Degree of } \\
\text { freedom }\end{array}$ & $\begin{array}{l}\text { Sum of } \\
\text { square }\end{array}$ & $\begin{array}{l}\text { Mean } \\
\text { square }\end{array}$ & $F$ value & $P$ value & $\begin{array}{l}\text { Contribution } \\
(\%)\end{array}$ \\
\hline Rake face roughness & 1 & 1.065 & 1.065 & 0.419 & 0.584 & 0.15 \\
Relief face roughness & 2 & 3.013 & 1.506 & 0.593 & 0.628 & 0.44 \\
Rake angle & 2 & 14.983 & 7.492 & 2.947 & 0.253 & 2.18 \\
Relief angle & 2 & 46.639 & 23.319 & 9.173 & 0.098 & 6.79 \\
Cutting speed & 2 & 16.093 & 8.046 & 3.165 & 0.240 & 2.34 \\
Feed per tooth & 2 & 272.434 & 136.217 & 53.583 & 0.018 & 39.65 \\
Axial cutting depth & 2 & 278.616 & 139.308 & 54.799 & 0.018 & 40.55 \\
Radial cutting depth & 2 & 49.171 & 24.586 & 9.671 & 0.094 & 7.16 \\
Error & 2 & 5.084 & 2.542 & & & 0.74 \\
Total & 17 & 687.098 & & & & 100.00 \\
\hline
\end{tabular}

tool design and tool grinding, relief face roughness is involved with the surface contact between tool and workpiece. The better cutting edge strength and less relief face roughness can be obtained by steady cutting process. For this reason, the relief angle, rake angle, and relief face roughness are more important than feed per tooth. Table 7 indicates that the primary factors influencing total removal volume are axial cutting depth $(40.550 \%)$, feed per tooth $(39.650 \%)$, radial cutting depth $(7.156 \%)$, and relief angle $(6.788 \%)$. Rake face roughness, relief face roughness, rake angle, and cutting speed are not significant factors.

\subsection{Multiple performance characteristics analysis}

First, based on Eq. (3), the $\mathrm{S} / \mathrm{N}$ ratio can be normalized for a better comparison of cutting performance. A higher relation with a distinguishing coefficient leads to a higher distinguishing coefficient. Following normalization, to compare cutting performance with the original sequences (ideal sequences/ $(1,1,1))$, they should be converted into grey relational coefficients by Eq. (4) so that the quantities range from
0.33 to 1 . Finally, the multiple quality characteristic grey relatedness is calculated with Eq. (5), In this study, the weighting values of each quality characteristic originate from the average values in Eq. (5), i.e., $\beta_{1}=0.333, \beta_{2}=0.333$, and $\beta_{3}=0.333$. Table 4 shows the grey relational grade of multiple performance characteristics. According to this table, the grey relational grade of the 11th group is maximum (1.000), implying that its multiple performance characteristic is the best result in 18 groups.

Variance analysis is performed to determine the influence of processing parameters on multiple performance characteristics by a statistical method. Based on the grey relatedness grade, the analysis of variance is performed. Table 8 summarizes those results. According to this table, the cutting speed and feed per tooth significantly influence the multiple quality characteristics, with a total contribution of $54.84 \%$. The other influencing factors are axial cutting depth, relief face roughness, rake angle, radial cutting depth, relief angle, and rake face roughness. The contributions of tool grinding precision, geometric angle, and cutting conditions on the multiple quality characteristics of HSC of AISI H13 tool steel are 11.75, 9.78 , and $73.11 \%$, respectively.
Table 8 ANOVA for multiple performance characteristics

$F_{0.1}(1,2)=8.53, F_{0.1}(2,2)=9.00$

\begin{tabular}{llllllll}
\hline Symbol & $\begin{array}{l}\text { Processing } \\
\text { parameter }\end{array}$ & $\begin{array}{l}\text { Degree of } \\
\text { freedom }\end{array}$ & $\begin{array}{l}\text { Sum of } \\
\text { square }\end{array}$ & $\begin{array}{l}\text { Mean } \\
\text { square }\end{array}$ & $F$ value & $P$ value & $\begin{array}{l}\text { Contribution } \\
(\%)\end{array}$ \\
\hline A & Rake face roughness & 1 & 0.001 & 0.001 & 0.147 & 0.738 & 0.39 \\
B & Relief face roughness & 2 & 0.035 & 0.017 & 2.127 & 0.320 & 11.36 \\
C & Rake angle & 2 & 0.016 & 0.008 & 0.992 & 0.502 & 5.30 \\
D & Relief angle & 2 & 0.014 & 0.007 & 0.843 & 0.543 & 4.50 \\
E & Cutting speed & 2 & 0.103 & 0.052 & 6.327 & 0.136 & 33.78 \\
F & Feed per tooth & 2 & 0.064 & 0.032 & 3.944 & 0.202 & 21.06 \\
G & Axial cutting depth & 2 & 0.041 & 0.020 & 2.494 & 0.286 & 13.31 \\
H & Radial cutting depth & 2 & 0.015 & 0.008 & 0.929 & 0.518 & 4.96 \\
Error & & 2 & 0.016 & 0.008 & & & 5.34 \\
Total & & 17 & 0.306 & & & & 100.00 \\
\hline
\end{tabular}




\subsection{Grinding efficiency analysis}

Table 2 indicates that the rake face roughness grinding time increases on average by $249 \mathrm{~s}$ (i.e., from $1.5 \pm 0.03$ to $0.5 \pm$ $0.03 \mu \mathrm{m}$ ), with grinding costs increasing by $26.35 \%$. Relief face roughness grinding time increases on average by $94 \mathrm{~s}$ (i.e., from $1.5 \pm 0.03$ to $1.0 \pm 0.03 \mu \mathrm{m}$ ) and by 738 s (i.e., from $1.5 \pm 0.03$ to $0.5 \pm 0.03 \mu \mathrm{m}$ ), with grinding costs increasing by 11.87 and $93.18 \%$, respectively. Tables 4 and 6 show the single quality characteristic ANOVA of flank wear rate and total removal volume. According to these tables, rake face roughness and relief face roughness were not significant factors. Therefore, with the $\mathrm{A} 2$ and $\mathrm{B} 3$ grinding conditions, tool grinding efficiency is increased by $147.02 \%$ (i.e., from a rake face roughness of $0.5 \pm 0.03$ and a relief face roughness of 0.5 $\pm 0.03 \mu \mathrm{m}$ to a rake face roughness of $1.5 \pm 0.03$ and a relief face roughness of $1.5 \pm 0.03 \mu \mathrm{m})$. Additionally, Tables 5 and 8 show the workpiece surface roughness quality characteristics and the multiple quality characteristic ANOVA. The above results demonstrate that the relief face roughness is a significant factor. Moreover, the rake face roughness is not a significant factor because the relief face comes into contact with the workpiece directly. Hence, with the A2 and B1 grinding conditions, tool grinding efficiency is raised by $18.57 \%$ (i.e., from a rake face roughness of $0.5 \pm 0.03 \mu \mathrm{m}$ to a rake face roughness of $1.5 \pm 0.03 \mu \mathrm{m})$.

\section{Conclusions}

Based on grey relational analysis and the Taguchi method, this study analyzes how production parameters for single quality characteristics and multiple quality characteristics influence cutting performance during the HSM of AISI H13 tool steel. Results of this study are only applicable to the HSC of AISI H13 tool steel. Based on the results of this study, we conclude the following:

1. For rough milling, tool life and metal removal volume are the primary evaluation indicators. ANOVA on flank wear rate indicates that cutting speed and relief angle are significant factors, with a total contribution of $79.93 \%$. ANOVA on metal removal volume yields that feed per tooth, axial cutting depth, radial cutting depth, and relief angle are significant factors, with a total contribution of $94.14 \%$. Additionally, ANOVA on multiple quality characteristics reveals that cutting speed and feed per tooth are primary consideration factors, with a total contribution of $54.84 \%$. Therefore, in rough machining, the primary consideration factors include cutting parameters, especially cutting speed and feed per tooth.

2. In finish machining, workpiece surface roughness is the primary evaluation indicator. ANOVA on workpiece surface roughness indicates that rake angle, relief angle, and relief face roughness are significant factors, with a total contribution of $86.86 \%$. Therefore, endmill design and grinding, especially relief angle design and grinding, are major factors in finish machining, as well as cutting parameter selection.

3. Regarding tool grinding efficiency, in rough machining, rake face and relief face roughness should not be regarded as significant factors. Thus, A2 grinding conditions (grit size of diamond wheel $=$ D64, grinding speed $=1,500 \mathrm{~m} /$ $\mathrm{min}$, and feed speed $=400 \mathrm{~mm} / \mathrm{min}$ ) for the rake face and B3 grinding conditions (grit size of diamond wheel $=\mathrm{D} 54$, grinding speed $=1,000 \mathrm{~m} / \mathrm{min}$, and feed speed $=400 \mathrm{~mm} /$ $\mathrm{min}$ ) for the relief face can be adopted to increase grinding efficiency by $147.02 \%$. In finish machining, because the relief face comes into direct contact with the workpiece, relief face roughness is a significant factor, unlike rake face roughness. Consequently, A2 grinding conditions (grit size of diamond wheel $=\mathrm{D} 64$, grinding speed $=1$, $500 \mathrm{~m} / \mathrm{min}$, and feed speed $=400 \mathrm{~mm} / \mathrm{min}$ ) for the rake face and B1 grinding conditions (grit size of diamond wheel $=\mathrm{D} 54$, grinding speed $=1,750 \mathrm{~m} / \mathrm{min}$, and feed speed $=10 \mathrm{~mm} / \mathrm{min}$ ) for the relief face can be adopted to increase grinding efficiency by $18.57 \%$.

Acknowledgments This work is partially supported by the National Science Council, Taiwan, under contract NSC100-2221-E-150-024.

Open Access This article is distributed under the terms of the Creative Commons Attribution License which permits any use, distribution, and reproduction in any medium, provided the original author(s) and the source are credited.

\section{References}

1. Li L, He N, Wang M, Wang ZG (2002) High speed cutting of Inconel 718 with coated carbide and ceramic inserts. J Mater Process Technol 129:127-130

2. Dolinsek S, Sustarsic B, Kopac J (2001) Wear mechanisms of tools in high speed cutting process. Wear 250:349-356

3. Schulz H, Moriwaki T (1992) High-speed machining. CIRP AnnManuf Technol 41:637-643

4. Fallböhmer P, Rodríguez CA, Özel T, Altan T (2000) High-speed machining of cast iron and alloy steels for die and mold manufacturing. J Mater Process Technol 98:104-115

5. Cui XB, Znao J, Tian XH (2013) Cutting forces, chip formation, and tool wear in high-speed face milling of AISI H13 steel with CBN tools. Int J Adv Manuf Technol 64:1737-1749

6. Fahad M, Mativenga PT, Sheikh MA (2012) A comparative study of multilayer and functionally graded coated tools in high-speed machining. Int J Adv Manuf Technol 62:43-57

7. Cui XB, Zhao J, Jia C, Zhou YH (2012) Surface roughness and chip formation in high-speed face milling AISI H13 steel. Int J Adv Manuf Technol 61:1-13

8. Benardos PG, Vosniakos GC (2003) Predicting surface roughness in machining a review. Int J Mach Tool Manuf 43:838-844 
9. Yin L, Spowage AC, Ramesh K, Huang H, Pickering JP, Vancoille EYJ (2003) Influence of microstructure on ultra-precision grinding of cemented carbides. Int J Mach Tool Manuf 44:533-543

10. Kwak JS (2004) Application of Taguchi and response surface methodologies for geometric error in surface grinding process. Int J Mach Tool Manuf 45:327-334

11. Kopac K, Krajnik P (2006) High-performance grinding — a review. J Mater Process Technol 175:278-284

12. Abdullah A, Pak A, Farahi M, Barzegari M (2007) Profile wear of resin-bonded nickel-coated diamond wheel and roughness in creepfeed grinding of cemented tungsten carbide. J Mater Process Technol 183:165-168

13. Ross PJ (1988) Taguchi techniques for quality engineering. McGrawHill, New York

14. Ghani JA, Choudhury IA, Hassan HH (2004) Application of Taguchi method in the optimization of end milling parameters. J Mater Process Technol 145:84-92

15. Saglam H, Yaldiz S, Unsacar F (2007) The effect of tool geometry and cutting speed on main cutting force and tool tip temperature. Mater Des 28:101-111

16. Çiçek A, Kıvak T, Samtaş G (2012) Application of Taguchi method for surface roughness and roundness error in drilling of AISI 316 stainless steel. Strojniski Vestn J Mech Eng 58:165-174

17. Deng JL (1989) Introduction to Grey system theory. J Grey Syst 1:1-24

18. Tsao CC (2009) Grey-Taguchi method to optimize the milling parameters of aluminum alloy. Int J Adv Manuf Technol 40:41-48
19. Gopalsamy BM, Mondal B, Ghosh S (2009) Optimization of machining parameters for hard machining grey relational theory approach and ANOVA. Int J Adv Manuf Technol 45:1068-1086

20. Lu HS, Chang CK, Hwang NC, Chung CT (2009) Grey relational analysis coupled with principal component analysis for optimization design of the cutting parameters in high-speed end milling. J Mater Process Technol 209:3808-3817

21. Sahoo AK, Baral AN, Rout AK, Routra BC (2012) Multi-objective optimization and predictive modeling of surface roughness and material removal rate in turning using grey relational and regression analysis. Procedia Eng 38:1606-1627

22. Tosun N (2006) Determination of optimum parameters for multiperformance characteristics in drilling by using grey relational analysis. Int J Adv Manuf Technol 26:450-455

23. Chang CK, Lu HS (2007) Design optimization of cutting parameters for side milling operations with multiple performance characteristics. Int J Adv Manuf Technol 32:18-26

24. Wang YC, Chen CH, Lee BY (2012) The design model of micro end-mills by the finite element method. Trans FAMENA 36: $41-50$

25. Chen CH, Wang YC, Lee BY (2012) The effect of surface roughness of end-mills on optimal cutting performance for high-speed machining. Strojniski Vvestn J Mech Eng 59:124-134

26. Chen JY, Lee BY, Chen CH (2007) Planning and analysis of grinding processes for end mills of cemented tungsten carbide. J Mater Process Technol 201:618-622 